\title{
Effect of Non-Uniform Temperature Gradient on the Onset of Rayleigh-Bénard- Magnetoconvection in Micropolar Fluid with Maxwell-Cattaneo Law
}

\author{
S Pranesh* and R V Kiran ${ }^{\dagger}$
}

\section{Abstract}

The effect of non-uniform temperature gradient on the onset of Rayleigh-Bénard magnetoconvection in a Micropolar fluid with Maxwell-Cattaneo law is studied using the Galerkin technique. The eigenvalue is obtained for free-free, rigid-free and rigid-rigid velocity boundary combinations with isothermal condition on the spinvanishing boundaries. A linear stability analysis is performed. The influence of various parameters on the onset of convection has been analyzed. One linear and five non-linear temperature profiles are considered and their comparative influence on onset of convection is discussed. The classical approach predicts an infinite speed for the propagation of heat. The present nonclassical theory involves a wave type heat transport (Second Sound) and does not suffer from the physically unacceptable drawback of infinite heat propagation speed.

Keywords: Rayleigh-Bénard Convection, Non-uniform basic temperature, magnetic field, Maxwell-Cattaneo law and Galerkin technique.

\footnotetext{
* Department of Mathematics, Christ University, Hosur Road, Bangalore 560 029, India, pranesh.s@christuniversity.in

† Department of Mathematics, Christ Junior College, Hosur Road, Bangalore 560 029, India, kiran.rv@cjc.christcollege.edu
} 


\section{Introduction}

The instability of Rayleigh-Bénard convection is due to the effect of thermal buoyancy. Theoretical studies of the onset of convection in classical viscous fluids with non-uniform heating have been made by Currie [1] with isothermal boundaries and by Nield [2] with adiabatic boundaries and showed that in the case of piecewise linear temperature profile the onset of convection could occur at a smaller Rayleigh number than of uniform heating or cooling. The non-uniform temperature gradient finds its origin in the transient heating or cooling at the boundaries and as a result the basic temperature profile depends explicitly on position and time. This has to be determined by solving the coupled momentum and energy equations. This coupling makes the problem very complicated. In the present study, therefore, we adopt a series of temperature profiles based on a simplification in the form of a quasi - static approximation (Currie [1], Lebon and Cloot [3]) that consists of freezing the temperature distribution at a given instant of time. In this method, we assume that the perturbation grows much faster than the initial state and hence freeze the initial state into some spatial distribution. This hypothesis is sufficient for our purpose because we are interested only in finding the conditions for the onset of convection. Even with these simplifications, the solutions to the variable-coefficients stability equation pose a problem because the temperature gradient varies with depth.

Convection in Micropolar fluid has been the subject of intensive study because of the remarkable physical properties of the fluid as well as its practical applications (see Power [4], Lukaszewicz [5] and Eringen [6]). Rayleigh-Bénard/Marangoni convection in Micropolar fluid with and without non-uniform temperature gradient has been investigated by many authors (Datta and Sastry [7], Bhattacharya and Jena [8], Siddheshwar and Pranesh [9, 10, 11, 12, 13, and 14] and Pranesh and Riya Baby [15]). The main results from all these studies are that for heating from below stationary convection is the preferred mode. All the above reported works are with classical Fourier heat flux law.

A well known consequence of Classical Fourier heat conduction law is that heat perturbations propagate with an infinite velocity. 194 
This drawback of the classical law motivated Maxwell [16], Cattaneo [17], Lindsay and Stranghan [18], Straughan and Franchi [19], Pranesh and Kiran [20] and Pranesh and Smita [21] to adopt a non-classical heat flux Maxwell-Cattaneo law in studying Rayleigh-Bénard / Marangoni convection to get rid of this unphysical results. This Maxwell-Cattaneo equation contains an extra inertial term with respect to the Fourier law

$$
\tau \frac{\mathrm{d} \overrightarrow{\mathrm{Q}}}{\mathrm{dt}}+\overrightarrow{\mathrm{Q}}=-\kappa \nabla \mathrm{T}
$$

where, $\vec{Q}$ is the heat flux, $\tau$ is a relaxation time and $\kappa$ is the heat conductivity. This heat conductivity equation and the conservation of energy equation introduce the hyperbolic equation, which describes heat propagation with finite speed. Puri and Jordan [22, 23], Puri and Kythe [24, 25] and Straughan [26] have studied other fluid mechanics problems by employing the Maxwell-Cattaneo heat flux law.

The objective of this paper is to replace the classical parabolic heat equation by non-classical Maxwell-Cattaneo Law and study the effect of non-uniform basic temperature gradients on the onset of Rayleigh-Bénard magnetoconvection in Micropolar fluids.

\section{Mathematical Formulation}

Consider an infinite horizontal layer of a Boussinesquian, electrically conducting fluid, with non-magnetic suspended particle of depth ' $d$ ' permeated by an externally applied uniform magnetic field normal to the fluid layer. Cartesian co-ordinate system is taken with origin in the lower boundary and z-axis vertically upwards. Let $\Delta \mathrm{T}$ be the temperature difference between the upper and lower boundaries. (See Figure (1)). 


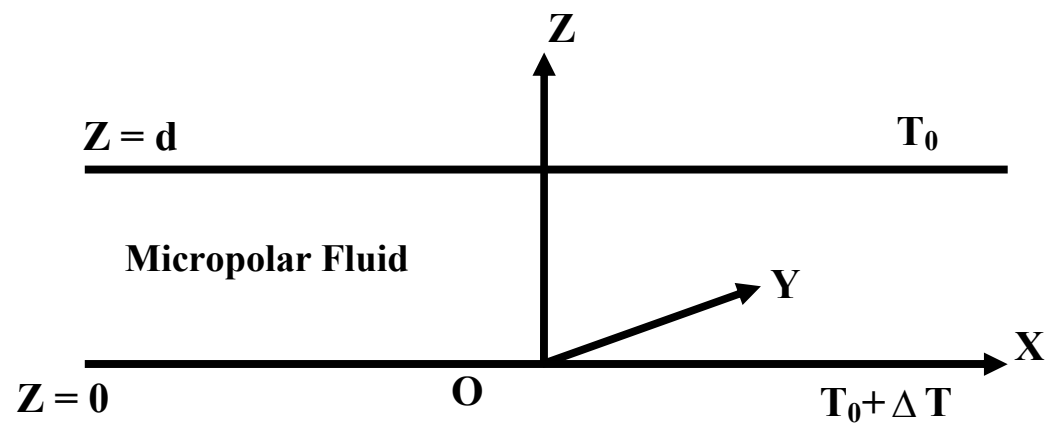

Figure 1. Schematic diagram of the Rayleigh-Bénard situation for a Micropolar fluid.

The governing equations for the Rayleigh-Bénard situation in a Boussinesquian fluid with suspended particles are

Continuity equation

$$
\nabla \cdot \vec{q}=0
$$

\section{Conservation of linear momentum}

$$
\rho_{\mathrm{o}}\left[\frac{\partial \overrightarrow{\mathrm{q}}}{\partial \mathrm{t}}+(\overrightarrow{\mathrm{q}} \cdot \nabla) \overrightarrow{\mathrm{q}}\right]=-\nabla \mathrm{p}-\rho \mathrm{g} \hat{\mathrm{k}}+(2 \zeta+\eta) \nabla^{2} \overrightarrow{\mathrm{q}}+\zeta \nabla \times \vec{\omega}+\mu_{\mathrm{m}}(\overrightarrow{\mathrm{H}} . \nabla) \overrightarrow{\mathrm{H}},
$$

Conservation of angular momentum

$$
\rho_{\mathrm{o}} \mathrm{I}\left[\frac{\partial \vec{\omega}}{\partial \mathrm{t}}+(\overrightarrow{\mathrm{q}} \cdot \nabla) \vec{\omega}\right]=\left(\lambda^{\prime}+\eta^{\prime}\right) \nabla(\nabla \cdot \vec{\omega})+\left(\eta^{\prime} \nabla^{2} \vec{\omega}\right)+\zeta(\nabla \times \overrightarrow{\mathrm{q}}-2 \vec{\omega}),
$$

Conservation of energy

$$
\frac{\partial \mathrm{T}}{\partial \mathrm{t}}+\left(\overrightarrow{\mathrm{q}}-\frac{\beta}{\rho_{\mathrm{o}} \mathrm{C}_{\mathrm{v}}} \nabla \times \vec{\omega}\right) \cdot \nabla \mathrm{T}=-\nabla \cdot \overrightarrow{\mathrm{Q}}
$$

Maxwell - Cattaneo heat flux law

$$
\tau\left[\dot{\overrightarrow{\mathrm{Q}}}+\vec{\omega}_{1} \times \overrightarrow{\mathrm{Q}}\right]=-\overrightarrow{\mathrm{Q}}-\kappa \nabla \mathrm{T},
$$




\section{Magnetic Induction equation}

$$
\frac{\partial \overrightarrow{\mathrm{H}}}{\partial \mathrm{t}}+(\overrightarrow{\mathrm{q}} \cdot \nabla) \overrightarrow{\mathrm{H}}=(\overrightarrow{\mathrm{H}} \cdot \nabla) \overrightarrow{\mathrm{q}}+\gamma_{\mathrm{m}} \nabla^{2} \overrightarrow{\mathrm{H}}
$$

\section{Equation of state}

$$
\rho=\rho_{\mathrm{o}}\left[1-\alpha\left(\mathrm{T}-\mathrm{T}_{\mathrm{o}}\right)\right]
$$

where, $\overrightarrow{\mathrm{q}}$ is the velocity, $\vec{\omega}$ is the spin, $\mathrm{T}$ is the temperature, $\mathrm{P}$ is the hydromagnetic pressure, $\rho$ is the density, $\rho_{\mathrm{o}}$ is the density of the fluid at reference temperature $\mathrm{T}=\mathrm{T}_{\mathrm{o}}, \gamma_{\mathrm{m}}=\frac{1}{\mu_{\mathrm{m}} \sigma}, \mu_{\mathrm{m}}$ is magnetic permeability, $\mathrm{g}$ is the acceleration due to gravity, $\zeta$ is the coupling viscosity coefficient or vortex viscosity, $\eta$ is the shear kinematic viscosity coefficient, $I$ is the moment of inertia, $\lambda^{\prime}$ and $\eta^{\prime}$ are the bulk and shear spin viscosity coefficient, $\beta$ is the Micropolar heat conduction coefficient, $\mathrm{C}_{\mathrm{v}}$ is the specific heat, $\kappa$ is the thermal conductivity, $\alpha$ is the co - efficient of thermal expansion, $\vec{\omega}_{1}=\frac{1}{2} \nabla \times \overrightarrow{\mathrm{q}}, \overrightarrow{\mathrm{Q}}$ is the heat flux vector and $\tau$ is the constant relaxation time.

\section{Basic State}

The basic state of the fluid being quiescent is described by

$$
\left.\begin{array}{l}
\overrightarrow{\mathrm{q}}_{\mathrm{b}}=0, \vec{\omega}_{\mathrm{b}}=0, P=\mathrm{P}_{\mathrm{b}}(\mathrm{z}), \rho=\rho_{\mathrm{b}}(\mathrm{z}), \vec{\omega}=\vec{\omega}_{\mathrm{b}}(\mathrm{z}), \\
\overrightarrow{\mathrm{H}}=\mathrm{H}_{0} \hat{\mathrm{k}}, \overrightarrow{\mathrm{Q}}=\left(0,0, \mathrm{Q}_{\mathrm{b}}(\mathrm{z})\right), \frac{\mathrm{dT}_{\mathrm{b}}}{\mathrm{dz}}=\frac{-\Delta \mathrm{T}}{\mathrm{d}} \mathrm{f}(\mathrm{z}) .
\end{array}\right\}
$$

The monotonic, non-dimensional basic temperature gradient $f(z)$ which is non-negative satisfies the condition $\int_{0}^{1} f(z) d z=1$. We 
have considered various steady state temperature gradients in this paper and these are defined below.

Table (1): Basic-State Temperature Gradients

\begin{tabular}{|c|c|c|}
\hline Model & $\begin{array}{c}\text { Basic temperature } \\
\text { gradients }\end{array}$ & $\mathbf{f ( z )}$ \\
\hline 1. & Linear & $\left\{\begin{array}{cc}\varepsilon^{-1} & 0 \leq \mathrm{z}<\varepsilon \\
0 & \varepsilon<\mathrm{z} \leq 1\end{array}\right.$ \\
\hline 2. & Heating from below & $\left\{\begin{array}{cc}0 & 0 \leq \mathrm{z}<1-\varepsilon \\
\varepsilon^{-1} & 1-\varepsilon<\mathrm{z} \leq 1\end{array}\right.$ \\
\hline 3. & Cooling from above & $\delta(\mathrm{z}-\varepsilon)$ \\
\hline 4. & Step function & $2(1-\mathrm{z})$ \\
\hline 5. & Inverted Parabolic & $2 \mathrm{z}$ \\
\hline 6. & Parabolic & \\
\hline
\end{tabular}

Equations (2), (4), (5) and (7) in the basic state specified by equation (8) respectively become

$$
\left.\begin{array}{l}
\frac{d P_{b}}{d z}=-\rho_{o} g \hat{k}, \frac{d \vec{Q}_{b}}{d z}=0, \vec{Q}_{b}=-\kappa \frac{d T_{b}}{d z}, \\
\rho_{b}=\rho_{o}\left[1-\alpha\left(T_{b}-T_{o}\right)\right], \frac{d^{2} T_{b}}{d z^{2}}=0 .
\end{array}\right\}
$$

\section{Linear Stability Analysis}

Let the basic state be disturbed by an infinitesimal thermal perturbation. We now have

$$
\left.\begin{array}{l}
\overrightarrow{\mathrm{q}}=\overrightarrow{\mathrm{q}}_{\mathrm{b}}+\overrightarrow{\mathrm{q}}^{\prime}, \vec{\omega}=\vec{\omega}_{\mathrm{b}}+\vec{\omega}^{\prime}, \mathrm{P}=\mathrm{P}_{\mathrm{b}}+\mathrm{P}^{\prime}, \overrightarrow{\mathrm{Q}}=\overrightarrow{\mathrm{Q}}_{\mathrm{b}}+\overrightarrow{\mathrm{Q}}^{\prime}, \\
\rho=\rho_{\mathrm{b}}+\rho^{\prime}, \mathrm{T}=\mathrm{T}_{\mathrm{b}}+\mathrm{T}^{\prime}, \overrightarrow{\mathrm{H}}=\overrightarrow{\mathrm{H}}_{0}+\overrightarrow{\mathrm{H}}^{\prime} .
\end{array}\right\}
$$


Effect of Non-Uniform Temperature Gradient $\quad$ Mapana J Sci, 11, 3(2012)

The primes indicate that the quantities are infinitesimal perturbations and subscript ' $b$ ' indicates basic state value.

Substituting equation (10) into equations (1) - (7) and using the basic state (9), we get linearised equation governing the infinitesimal perturbations in the form:

$$
\begin{gathered}
\nabla \cdot \overrightarrow{\mathrm{q}}^{\prime}=0, \\
\rho_{0}\left[\frac{\partial \vec{q}^{\prime}}{\partial t}\right]=-\nabla P^{\prime}-\rho^{\prime} g \hat{k}+(2 \zeta+\eta) \nabla^{2} \vec{q}^{\prime} \\
+\left(\zeta \nabla \times \vec{\omega}^{\prime}\right)+\mu_{m}\left(H_{0} \hat{k} \cdot \nabla\right) \vec{H}^{\prime}, \\
\rho_{\mathrm{o}} \mathrm{I}\left[\frac{\partial \vec{\omega}^{\prime}}{\partial \mathrm{t}}\right]=\left(\lambda^{\prime}+\eta^{\prime}\right) \nabla\left(\nabla \vec{\omega}^{\prime}\right)+\left(\eta^{\prime} \nabla^{2} \vec{\omega}^{\prime}\right)+\zeta\left(\nabla \times \overrightarrow{\mathrm{q}}^{\prime}-2 \vec{\omega}^{\prime}\right), \\
\frac{\partial \mathrm{T}^{\prime}}{\partial \mathrm{t}}=\frac{\Delta \mathrm{T}}{\mathrm{d}} \mathrm{f}(\mathrm{z})\left[\overrightarrow{\mathrm{q}}^{\prime}-\frac{\beta}{\rho_{\mathrm{o}} \mathrm{C}_{\mathrm{v}}} \nabla \times \vec{\omega}^{\prime}\right]-\nabla \cdot \overrightarrow{\mathrm{Q}}^{\prime}, \\
\left.1+\tau \frac{\partial}{\partial \mathrm{t}}\right] \overrightarrow{\mathrm{Q}}^{\prime}=-\frac{1}{2} \chi_{1} \frac{\Delta \mathrm{T}}{\mathrm{d}}\left(\frac{\partial \overrightarrow{\mathrm{q}}^{\prime}}{\partial \mathrm{z}}-\nabla \mathrm{W}^{\prime}\right)-\kappa \nabla \mathrm{T}^{\prime}, \\
\frac{\partial \overrightarrow{\mathrm{H}}^{\prime}}{\partial \mathrm{t}}=\gamma_{\mathrm{m}} \nabla^{2} \overrightarrow{\mathrm{H}}^{\prime}+\mathrm{H}_{0} \frac{\partial \overrightarrow{\mathrm{q}}^{\prime}}{\partial \mathrm{z}}, \\
\rho^{\prime}=-\alpha \rho_{\mathrm{o}} \mathrm{T}^{\prime} .
\end{gathered}
$$

where $\chi_{1}=\tau \kappa$.

Operating divergence on the equation (15) and substituting in equation (14), on using equation (11), we get

$$
\begin{aligned}
\left(1+\tau \frac{\partial}{\partial t}\right) \frac{\partial T^{\prime}}{\partial t}= & \left(1+\tau \frac{\partial}{\partial t}\right) \frac{\Delta T}{d} f(z)\left(W^{\prime}-\frac{\beta}{\rho_{0} C_{v}} \Omega_{z}\right) \\
& +\kappa \nabla^{2} T^{\prime}-\frac{1}{2} \chi_{1} \frac{\Delta T}{d} f(z)\left(\nabla^{2} W^{\prime}\right),
\end{aligned}
$$

where $\Omega=\nabla \times \vec{\omega}^{\prime}$. 
The perturbation equation (12), (13), (16) and (18) are non dimensionalised using the following definition:

$$
\left.\begin{array}{l}
\left.\left(\mathrm{x}^{*}, \mathrm{y}^{*}, \mathrm{z}^{*}\right)=\frac{(\mathrm{x}, \mathrm{y}, \mathrm{z})}{\mathrm{d}}, \mathrm{W}^{*}=\frac{\mathrm{W}^{\prime}}{(\mathrm{\kappa} / \mathrm{d})}, \vec{\omega}^{*}=\frac{\omega^{\prime}}{\kappa / \mathrm{d}^{2}}\right), \mathrm{t}^{*}=\frac{\mathrm{t}}{\left(\mathrm{d}^{2} / \mathrm{\kappa}\right)}, \\
\left.\mathrm{T}^{*}=\frac{\mathrm{T}^{\prime}}{\Delta \mathrm{T}}, \Omega^{*}=\frac{\Omega_{\mathrm{z}}}{\left(\kappa / \mathrm{d}^{3}\right.}\right), \mathrm{H}^{*}=\frac{\mathrm{H}^{\prime}}{\mathrm{H}_{0}} .
\end{array}\right\}
$$

Using equation (17) in (12), operating curl twice on the resulting equation, operating curl once on equation (13) and nondimensionalising the two resulting equation and also equations (16) and (18), we get

$$
\begin{aligned}
& \frac{1}{\operatorname{Pr}} \frac{\partial}{\partial \mathrm{t}}\left(\nabla^{2} \mathrm{~W}\right)=\mathrm{R} \nabla_{1}^{2} \mathrm{~T}+\left(1+\mathrm{N}_{1}\right) \nabla^{4} \mathrm{~W}+\mathrm{N}_{1} \nabla^{2} \Omega_{\mathrm{z}}+\mathrm{Q} \frac{\operatorname{Pr}}{\operatorname{Pm}} \nabla^{2}\left(\frac{\partial \mathrm{H}_{\mathrm{z}}}{\partial \mathrm{z}}\right), \\
& \frac{\mathrm{N}_{2}}{\operatorname{Pr}} \frac{\partial}{\partial \mathrm{t}}\left(\Omega_{\mathrm{z}}\right)=\mathrm{N}_{3} \nabla^{2} \Omega_{\mathrm{z}}-\mathrm{N}_{1} \nabla^{2} \mathrm{~W}-2 \mathrm{~N}_{1} \Omega_{\mathrm{z}}, \\
& \frac{\partial \mathrm{H}_{\mathrm{z}}}{\partial \mathrm{t}}=\frac{\partial \mathrm{W}}{\partial \mathrm{z}}+\frac{\mathrm{Pr}}{\operatorname{Pm}} \nabla^{2} \mathrm{H}_{\mathrm{z}}, \\
& \left(1+2 C \frac{\partial}{\partial t}\right) \frac{\partial T}{\partial t}=\left(1+2 C \frac{\partial}{\partial t}\right) \mathrm{f}(\mathrm{z}) W-\left(1+2 C \frac{\partial}{\partial t}\right) N_{5} \mathrm{f}(\mathrm{z}) \Omega_{z} \\
& +\nabla^{2} T-C \mathrm{f}(\mathrm{z}) \nabla^{2} W,
\end{aligned}
$$

where the asterisks have been dropped for simplicity and the nondimensional parameters $\mathrm{N}_{1}, \mathrm{~N}_{3}, \mathrm{~N}_{5}, \mathrm{R}, \mathrm{Q}, \mathrm{Pr}, \mathrm{Pm}$ and $\mathrm{C}$ are as defined as

$$
\begin{gathered}
\mathrm{N}_{1}=\frac{\zeta}{\zeta+\eta} \quad \text { (coupling parameter), } \\
\mathrm{N}_{3}=\frac{\eta^{\prime}}{(\zeta+\eta) \mathrm{d}^{2}} \quad \text { (couple stress parameter), } \\
\mathrm{N}_{5}=\frac{\beta}{\rho_{\mathrm{o}} \mathrm{C}_{\mathrm{v}} \mathrm{d}^{2}} \quad(\text { micropolar heat conduction parameter), }
\end{gathered}
$$


Effect of Non-Uniform Temperature Gradient $\quad$ Mapana J Sci, 11, 3(2012)

$$
\begin{gathered}
\mathrm{R}=\frac{\rho_{\mathrm{o}} \alpha \mathrm{g} \Delta \mathrm{Td}^{3}}{\kappa(\zeta+\eta)} \quad \text { (Rayleigh number), } \\
\mathrm{Q}=\frac{\mu_{\mathrm{m}} \overrightarrow{\mathrm{H}}_{\mathrm{o}} \mathrm{d}^{2}}{\gamma_{\mathrm{m}}(\zeta+\eta)} \quad \text { (Chandrasekhar Number), } \\
\operatorname{Pr}=\frac{\zeta+\eta}{\rho_{\mathrm{o}} \kappa} \quad \text { (Prandtl Number), } \\
\operatorname{Pm}=\frac{\zeta+\eta}{\gamma_{\mathrm{m}}} \quad \text { (Magnetic Prandtl Number), } \\
\mathrm{C}=\frac{\tau \kappa}{2 \mathrm{~d}^{2}} \quad \text { (Cattaneo number). }
\end{gathered}
$$

The infinitesimal perturbation $\mathrm{W}, \Omega_{\mathrm{z}}, \mathrm{H}_{\mathrm{z}}$ and $\mathrm{T}$ are assumed to be periodic waves and hence these permit a normal mode solution in the form

$$
\left[\begin{array}{l}
\mathrm{W} \\
\Omega_{\mathrm{z}} \\
\mathrm{H}_{\mathrm{z}} \\
\mathrm{T}
\end{array}\right]=\left[\begin{array}{l}
\mathrm{W}(\mathrm{z}) \mathrm{e}^{\mathrm{i}(\mathrm{lx}+\mathrm{my})} \\
\mathrm{G}(\mathrm{z}) \mathrm{e}^{\mathrm{i}(\mathrm{lx}+\mathrm{my})} \\
\mathrm{H}_{\mathrm{z}}(\mathrm{z}) \mathrm{e}^{\mathrm{i}(1 \mathrm{x}+\mathrm{my})} \\
\mathrm{T}(\mathrm{z}) \mathrm{e}^{\mathrm{i}(\mathrm{l}+\mathrm{my})}
\end{array}\right]
$$

where, 1 and $m$ are horizontal components of the wave number $\vec{a}$. Substituting equation (24) into equations (20)-(23), we get

$$
\begin{gathered}
\left(1+N_{1}\right)\left(D^{2}-a^{2}\right)^{2} W+N_{1}\left(D^{2}-a^{2}\right) G-R a^{2} T \\
+Q \frac{\operatorname{Pr}}{P m}\left(D^{2}-a^{2}\right)\left(D H_{z}\right)=0, \\
2 \mathrm{~N}_{1} \mathrm{G}-\mathrm{N}_{3}\left(\mathrm{D}^{2}-\mathrm{a}^{2}\right) \mathrm{G}+\mathrm{N}_{1}\left(\mathrm{D}^{2}-\mathrm{a}^{2}\right) \mathrm{W}=0, \\
\mathrm{DW}+\frac{\operatorname{Pr}}{\operatorname{Pm}}\left(\mathrm{D}^{2}-\mathrm{a}^{2}\right) \mathrm{H}_{\mathrm{z}}=0, \\
\mathrm{f}(\mathrm{z})\left(\mathrm{W}-\mathrm{N}_{5} \mathrm{G}\right)+\left(\mathrm{D}^{2}-\mathrm{a}^{2}\right) \mathrm{T}-\mathrm{Cf}(\mathrm{z})\left(\mathrm{D}^{2}-\mathrm{a}^{2}\right) \mathrm{W}=0 .
\end{gathered}
$$

where $\mathrm{D}=\frac{\mathrm{d}}{\mathrm{dz}}$. 
Eliminating $\mathrm{H}_{\mathrm{z}}$ between equations (25) and (27), we get

$$
\left(1+N_{1}\right)\left(D^{2}-a^{2}\right)^{2} W+N_{1}\left(D^{2}-a^{2}\right) G-R a^{2} T-Q D^{2} W=0,
$$

We now apply the single-term Galerkin method to equations (26), (28) and (29) that gives general results on the eigen value of the problem for various basic temperature gradients using simple, polynomial, trial functions for the lowest eigen value. Now we multiplying equation (29) by $\mathrm{W}$, equation (26) by $\mathrm{G}$ and equation (28) by $\mathrm{T}$, integrating the resulting equation by parts with respect to $\mathrm{z}$ from 0 to 1 and taking $\mathrm{W}=\mathrm{AW}_{1}, \mathrm{G}=\mathrm{BG}_{1}$ and $\mathrm{T}=\mathrm{ET}_{1}$ in which $A, B$ and $E$ are constants with $W_{1}, G_{1}$ and $T_{1}$ are trial functions. This procedure yields the following equation for the Rayleigh number R.

$$
R=\frac{\left\langle T_{1}\left(D^{2}-a^{2}\right) T_{1}\right\rangle\left[Y_{1} Y_{2}+N_{1}^{2} Y_{3}\right]}{a^{2}\left\langle W_{1} T_{1}\right\rangle Y_{4}}
$$

where,

$$
\begin{aligned}
Y_{1}= & \left(1+N_{1}\right)\left\langle W_{1}\left(D^{2}-a^{2}\right)^{2} W_{1}\right\rangle-Q\left\langle W_{1} D^{2} W_{1}\right\rangle, \\
Y_{2}= & N_{3}\left\langle G_{1}\left(D^{2}-a^{2}\right) G_{1}\right\rangle-2 N_{1}\left\langle G_{1}^{2}\right\rangle, \\
Y_{3}= & \left\langle G_{1}\left(D^{2}-a^{2}\right) W_{1}\right\rangle\left\langle W_{1}\left(D^{2}-a^{2}\right) G_{1}\right\rangle, \\
Y_{4}= & N_{1} N_{5}\left\langle G_{1}\left(D^{2}-a^{2}\right) W_{1}\right\rangle\left\langle\mathrm{f}(\mathrm{z}) T_{1} G_{1}\right\rangle \\
& +Y_{2}\left[C\left\langle T_{1} \mathrm{f}(\mathrm{z})\left(D^{2}-a^{2}\right) W_{1}\right\rangle-\left\langle\mathrm{f}(\mathrm{z}) T_{1} W_{1}\right\rangle\right] .
\end{aligned}
$$

In the equation (30), $\langle---\rangle$ denotes integration with respect to $z$ between $z=0$ and $z=1$. We note here that $R$ in equation (30) is a functional and the Euler - Lagrange equations for the extremisation of $R$ are equations (26), (28) and (29).

The value of critical Rayleigh number depends on the boundaries. In this paper we consider the following boundary combinations: 
1. Free-free isothermal, no-spin

$$
\mathrm{W}=\mathrm{D}^{2} \mathrm{~W}=\mathrm{T}=\mathrm{G}=0, \quad \text { at } \quad \mathrm{z}=0,1 .
$$

2. Rigid-rigid isothermal, no-spin

$$
\mathrm{W}=\mathrm{DW}=\mathrm{T}=\mathrm{G}=0, \quad \text { at } \quad \mathrm{z}=0,1 .
$$

3. Rigid-free isothermal, no-spin

$$
\begin{array}{lll}
\mathrm{W}=\mathrm{DW}=\mathrm{T}=\mathrm{G}=0 & \text { at } & \mathrm{z}=0, \\
\mathrm{~W}=\mathrm{D}^{2} \mathrm{~W}=\mathrm{T}=\mathrm{G}=0 & \text { at } & \mathrm{z}=1 .
\end{array}
$$

Trial functions satisfying the boundary conditions are given below. Free-free condition $\mathrm{W}_{1}=\mathrm{z}^{4}-2 \mathrm{z}^{3}+\mathrm{z}$,

Rigid-rigid condition $W_{1}=z^{4}-2 z^{3}+z^{2}$,

Rigid-free condition $W_{1}=2 z^{4}-5 z^{3}+3 z^{2}$,

Isothermal condition $T_{1}=z(1-z)$,

no-spin condition $\mathrm{G}_{1}=\mathrm{z}(1-\mathrm{z})$.

\section{Results and Discussion}

In this paper, we study the classical Rayleigh-Bénard magnetoconvection in Micropolar fluids in presence of nonuniform temperature gradients by replacing the classical Fourier heat flux law by a non-classical Maxwell-Cattaneo heat flux law. Keeping in mind the laboratory and geophysical problem, the following types of boundaries have been investigated:

(i) Free-free isothermal, no-spin condition,

(ii) Rigid-rigid isothermal, no-spin condition and

(iii) Rigid-free isothermal, no-spin condition.

One uniform and five non-uniform basic temperature gradients are chosen for study. We find that $R_{C 1}=R_{C 5}=R_{C 6} \neq R_{C 4}$ and $R_{C 2}=R_{C 3} \neq$ $\mathrm{R}_{\mathrm{C} 4}$ for the symmetric boundary combination. On the basis of this following grouping of non-uniform temperature profile can be made. 


\begin{tabular}{|c|c|c|}
\hline Group 1 & Group 2 & Group 3 \\
\hline \hline Linear $\left(\mathrm{R}_{\mathrm{C} 1}\right)$ & Piecewise linear heating from & Step function \\
Inverted & below $\left(\mathrm{R}_{\mathrm{C} 2}\right)$ & $\left(\mathrm{R}_{\mathrm{C} 4}\right)$ \\
parabolic $\left(\mathrm{R}_{\mathrm{C} 5}\right)$ & Piecewise linear cooling from & \\
Parabolic $\left(\mathrm{R}_{\mathrm{C} 6}\right)$ & above $\left(\mathrm{R}_{\mathrm{C} 3}\right)$ & \\
\hline
\end{tabular}

$R_{\mathrm{Ci}}$ ( $\mathrm{i}=1$ to 6 ) in the table are the critical Rayleigh numbers corresponding to the six basic temperature gradients. In the case of rigid-free boundaries (non-symmetric boundary combinations) no two $R_{\mathrm{Ci}}$ are the same. In the non-symmetric case we find that,

$$
\mathrm{R}_{\mathrm{C} 4}<\mathrm{R}_{\mathrm{C} 3}<\mathrm{R}_{\mathrm{C} 2}<\mathrm{R}_{\mathrm{C} 6}<\mathrm{R}_{\mathrm{C} 1}<\mathrm{R}_{\mathrm{C} 5}
$$

For symmetric/non-symmetric boundaries we find that the step function is the most destabilizing basic temperature and inverted parabolic is the most stabilizing basic temperature distribution.

In the case of piecewise linear and step function profiles, the critical Rayleigh number $R_{C}$ depends on the thermal depth $\varepsilon_{c}$, in addition to depending on the parameters of the problem.

Table (2): Isothermal: $\mathrm{N}_{1}=0.1, \mathrm{~N}_{3}=2.0, \mathrm{~N}_{5}=1.5, \mathrm{C}=0.01, \mathrm{Q}=10$.

\begin{tabular}{|c|c|c|c|c|c|c|}
\hline Boundary & \multicolumn{2}{|c|}{ Free-Free } & \multicolumn{2}{c|}{ Rigid-Rigid } & \multicolumn{2}{c|}{ Rigid-Free } \\
\hline \hline \multicolumn{1}{|c|}{ Profile } & $\varepsilon_{\mathrm{c}}$ & Ratio of $\mathrm{R}_{\mathrm{Ci}}$ & $\varepsilon_{\mathrm{c}}$ & Ratio of $\mathrm{R}_{\mathrm{C} i}$ & $\varepsilon_{\mathrm{c}}$ & Ratio of $\mathrm{R}_{\mathrm{Ci}}$ \\
\hline \hline $\begin{array}{l}\text { Heating from } \\
\text { below }\end{array}$ & 0.72 & $\mathrm{R}_{\mathrm{C} 2}=\mathrm{R}_{\mathrm{C} 1} / 1.1364$ & 0.70 & $\mathrm{R}_{\mathrm{C} 2}=\mathrm{R}_{\mathrm{C} 1} / 1.3498$ & 0.76 & $\mathrm{R}_{\mathrm{C} 2}=\mathrm{R}_{\mathrm{C} 1} / 1.1606$ \\
\hline \hline $\begin{array}{l}\text { Cooling from } \\
\text { above }\end{array}$ & 0.72 & $\mathrm{R}_{\mathrm{C} 3}=\mathrm{R}_{\mathrm{C} 1} / 1.1364$ & 0.70 & $\mathrm{R}_{\mathrm{C} 3}=\mathrm{R}_{\mathrm{C} 1} / 1.3498$ & 0.65 & $\mathrm{R}_{\mathrm{C} 3}=\mathrm{R}_{\mathrm{C} 1} / 1.3416$ \\
\hline \hline Step function & 0.52 & $\mathrm{R}_{\mathrm{C} 4}=\mathrm{R}_{\mathrm{C} 1} / 1.9221$ & 0.50 & $\mathrm{R}_{\mathrm{C} 4}=\mathrm{R}_{\mathrm{C} 1} / 2.3350$ & 0.54 & $\mathrm{R}_{\mathrm{C} 4}=\mathrm{R}_{\mathrm{C} 1} / 2.1317$ \\
\hline \hline $\begin{array}{l}\text { Inverted } \\
\text { Parabolic }\end{array}$ & -- & $\mathrm{R}_{\mathrm{C} 5}=\mathrm{R}_{\mathrm{C} 1}$ & -- & $\mathrm{R}_{\mathrm{C} 5}=\mathrm{R}_{\mathrm{C} 1}$ & -- & $\mathrm{R}_{\mathrm{C} 5}=\mathrm{R}_{\mathrm{C} 1} / 0.8957$ \\
\hline \hline Parabolic & -- & $\mathrm{R}_{\mathrm{C} 6}=\mathrm{R}_{\mathrm{C} 1}$ & -- & $\mathrm{R}_{\mathrm{C} 6}=\mathrm{R}_{\mathrm{C} 1}$ & -- & $\mathrm{R}_{\mathrm{C} 6}=\mathrm{R}_{\mathrm{C} 1} / 1.1042$ \\
\hline
\end{tabular}


Tables (2) provide information on the critical thermal depth $\varepsilon_{\mathrm{c}}$ that yields the critical eigenvalues for different boundary combinations in respect of all relevant basic temperature gradients. Figures (2)(4) are the plot of critical Rayleigh number $R_{C}$ versus Cattaneo number $C$, for different values of (a) coupling parameter $\mathrm{N}_{1}$, (b) couples stress parameter $\mathrm{N}_{3}$, (c) Micropolar heat condition parameter $\mathrm{N}_{5}$ and for different Chandrasekhar number $\mathrm{Q}$ and different basic temperature gradient for free-free, rigid-rigid and rigid-free boundaries respectively.

From these figures following observation are made:

1. As $C$ increases $R_{C}$ decreases, $C$ is the scaled relaxation time and it accelerates the onset of convection. Increase in $\mathrm{C}$ leads to narrowing of the convection cells and thus lowering of the critical Rayleigh number. It is also observed from the figures that influence of $\mathrm{C}$ is dominant for small values because the convection cells have fixed aspect ratio.

2. The increase in $\mathrm{N}_{1}$ increases $\mathrm{R}_{\mathrm{C}}$. Increase in $\mathrm{N}_{1}$ indicates the increase in the concentration of microelements. These elements consume the greater part of the energy in forming the gyrational velocities and as a result the onset of convection is delayed. From these we conclude that increase $\mathrm{N}_{1}$ stabilize the system.

3. As $\mathrm{N}_{3}$ increases $R_{C}$ decreases, because when $\mathrm{N}_{3}$ increases the couple stress of the fluid increases, which causes the microroation to decrease. Therefore, increase in $\mathrm{N}_{3}$ destabilizes the system.

4. When $\mathrm{N}_{5}$ increases the heat induced in to the fluid due to these microelements also increases, thus reducing the heat transfers from bottom to top. The decrease in heat transfer is responsible for delaying onset of instability. Therefore, increase in $\mathrm{N}_{5}$ increase $\mathrm{R}_{\mathrm{C}}$ and thereby stabilizes the system.

5. Increase in $Q$ increases the $R_{C}$. When the magnetic field strength permeating the medium is considerably strong, it induces viscosity into the fluid, and the magnetic lines are distorted by convection. Then these magnetic lines hinder 
the growth of disturbances, leading to the delay in the onset of instability. However, the viscosity produced by the magnetic field lessens the rotation of the fluid particles.

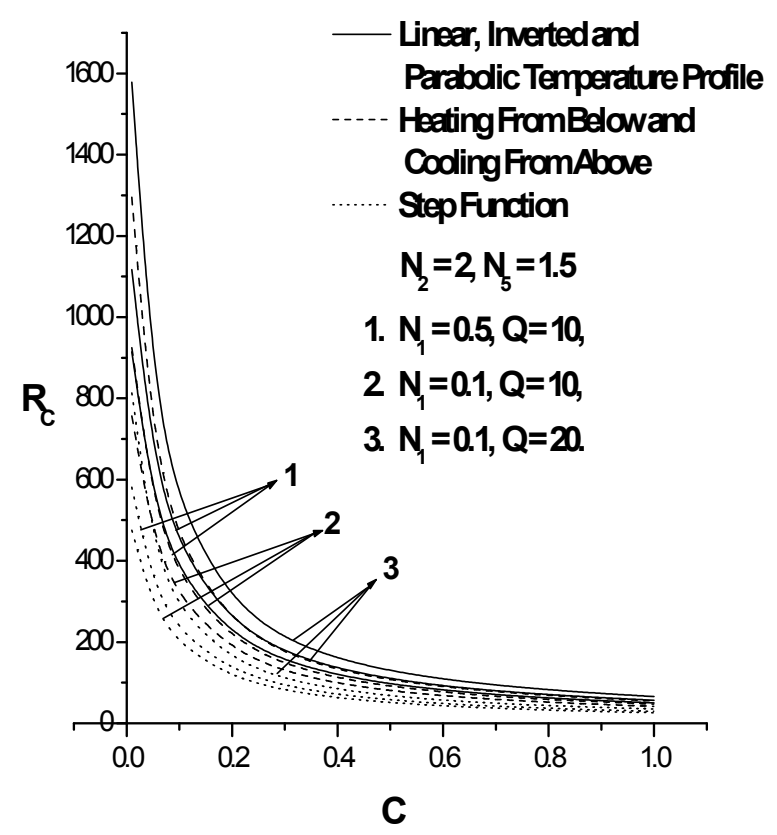

(a) 
Effect of Non-Uniform Temperature Gradient Mapana J Sci, 11, 3(2012)

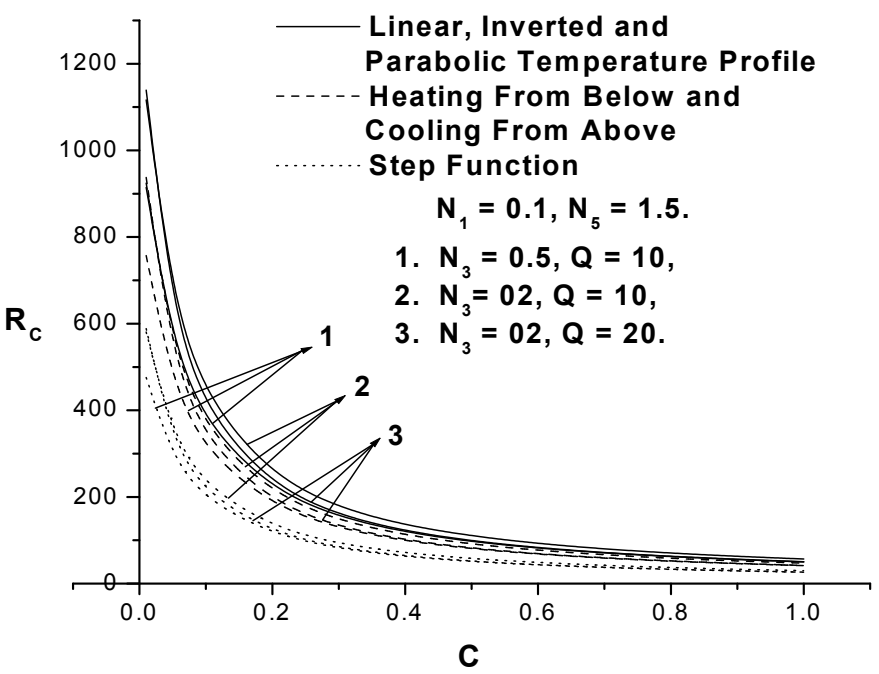

(b)

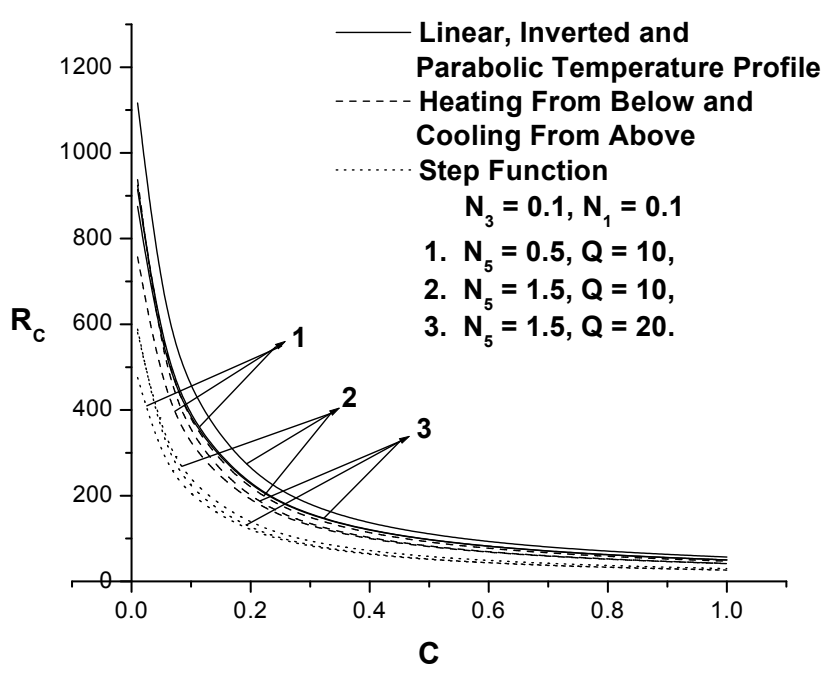

(c)

Figure 2. Plot of critical Rayleigh number $R_{C}$ Vs. Cattaneo number $C$ with respect to free-free isothermal no-spin boundary condition for different values of Q for (a) $\mathrm{N}_{1}$, (b) $\mathrm{N}_{3}$, (c) $\mathrm{N}_{5}$ and for different non-uniform basic temperature gradients. 


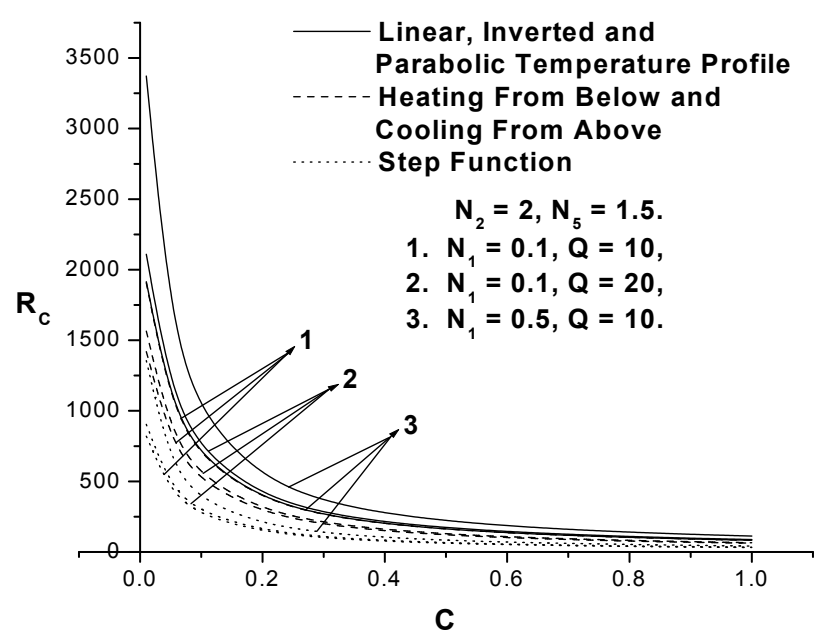

(a)

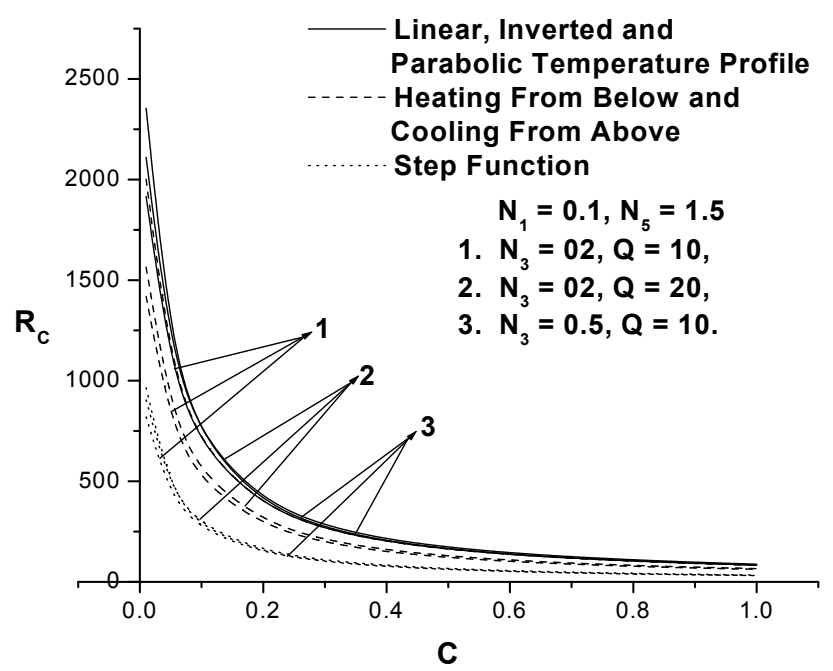

(b) 
Effect of Non-Uniform Temperature Gradient Mapana J Sci, 11, 3(2012)

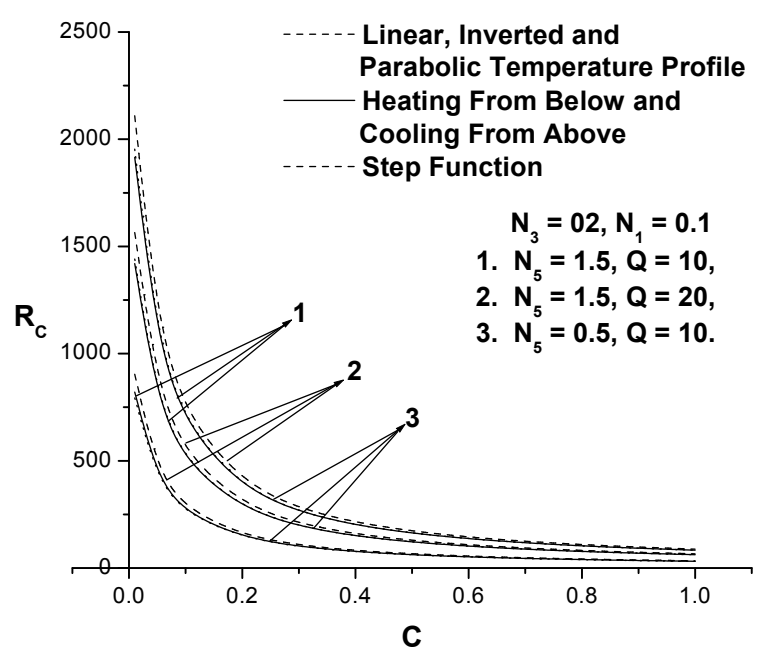

(c)

Figure 3. Plot of critical Rayleigh number $R_{C}$ Vs. Cattaneo number $C$ with respect to rigid-rigid isothermal no-spin boundary condition for different values of $Q$ for (a) $N_{1}$, (b) $N_{3}$, (c) $N_{5}$ and for different non-uniform basic temperature gradients.

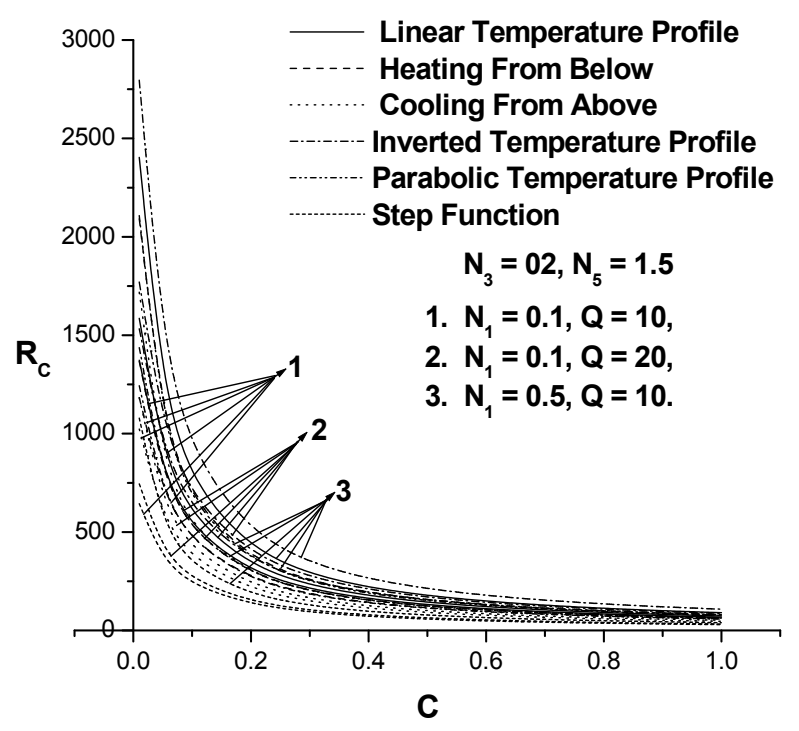

(a) 


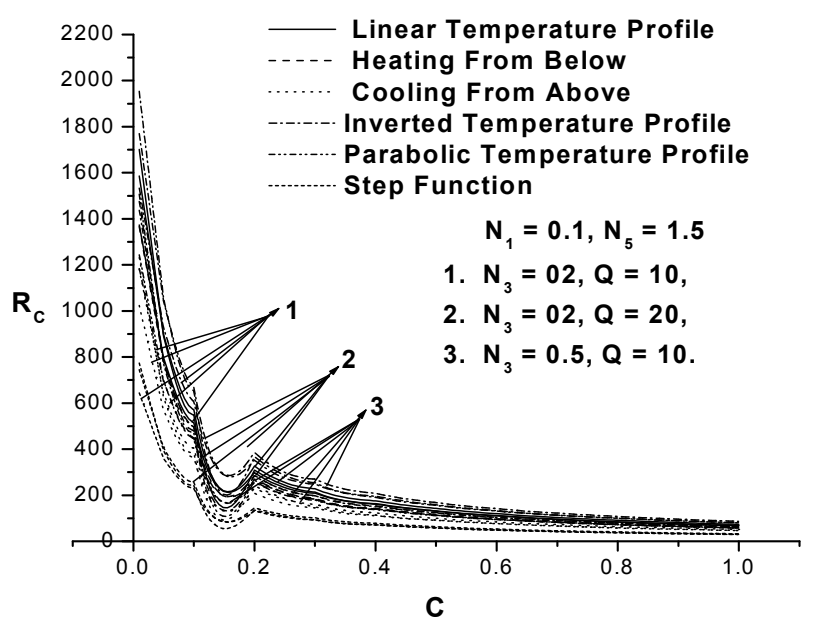

(b)

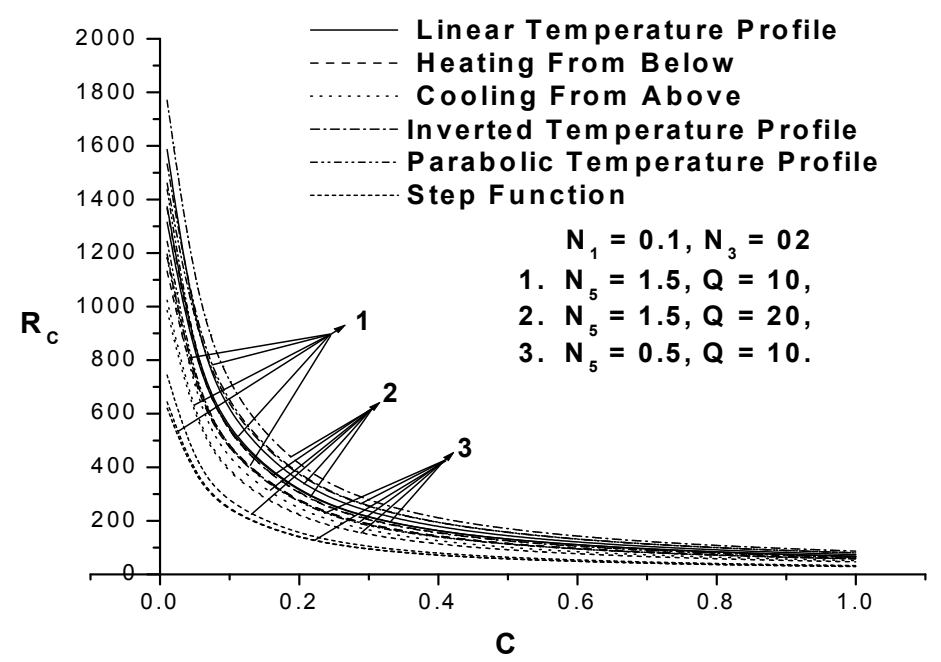

(c)

Figure 4. Plot of critical Rayleigh number $R_{C}$ Vs. Cattaneo number $C$ with respect to rigid-free isothermal no-spin boundary condition for different values of Q for (a) $\mathrm{N}_{1}$, (b) $\mathrm{N}_{3}$, (c) $\mathrm{N}_{5}$ and for different non-uniform basic temperature gradients. 


\section{Conclusions}

Following conclusions are drawn from the problem:

The inverted parabolic basic temperature profile is most stabilizing temperature profile. The step function basic temperature profile is most destabilizing temperature profile.

1. By creating conditions for appropriate basic temperature gradients we can also make a prior decision on advancing or delaying convection.

2. By adjusting the Chandrasekhar number $\mathrm{Q}$ we can control the convection.

3. Rayleigh-Bénard convection in Newtonian fluids may be delayed by adding micron sized suspended particles.

4. $\mathrm{R}_{\mathrm{C}}^{\mathrm{RR}}>\mathrm{R}_{\mathrm{C}}^{\mathrm{RF}}>\mathrm{R}_{\mathrm{C}}^{\mathrm{FF}}$ where, the superscripts correspond to the three different velocity boundary combinations.

5. $\mathrm{R}_{\mathrm{c}}^{\mathrm{HHE}}<\mathrm{R}_{\mathrm{c}}^{\mathrm{PHE}}$ where, HHE - Hyperbolic heat equation and PHE - Parabolic heat equation.

6. The non-classical Maxwell-Cattaneo heat flux law involves a hyperbolic type heat transport equation that predicts finite speeds of heat wave propagation. Hence it does not suffer from the physically unacceptable drawback of infinite heat propagation speed predicted by the parabolic heat equation. The classical Fourier flux law overpredicts the critical Rayleigh number compared to that predicted by the nonclassical law.

\section{Acknowledgment}

The authors would like to thank management of Christ University, Bangalore for their support in completing this work. 


\section{References}

[1] I G Currie, The effect of heating rate on the stability of stationary fluids, J. Fluid Mechanics, vol. 29, pp. 337-347, 1967.

[2] D A Nield, The onset of transient convective instability, J Fluid Mech., vol. 71, pp. 3-11, 1975.

[3] G Lebon and A Cloot, Effects of non-uniform temperature gradients on Bénard-Marangoni instability, J. Non-Equin. Thermodyn., vol. 6, pp. 15-30, 1981.

[4] H Power, Bio-Fluid Mechanics, Advances in fluid mechanics, W.I.T. Press, UK, 1995.

[5] Lukaszewicz, Micropolar fluid theory and applications, Birkhauser Boston, M. A., USA, 1998.

[6] A C Eringen, Microcontinuum fluid theories, Springer Verlag, 1999.

[7] A B Datta and V U D Sastry, Thermal instability of a horizontal layer of micropolar fluid heated from below, Int. J. Engg. Sci., vol. 14, pp. 631-637, 1976.

[8] S P Bhattacharya and S K Jena, Thermal instability of a horizontal layer of micropolar fluid with heat source, Int. J. Engg. Sci., vol. 23, pp. 13-26, 1976.

[9] P G Siddheshwar and S Pranesh, Magnetoconvection in a micropolar fluid, Int. J. Engng. Sci., vol. 36, pp. 1173-1181, 1998.

[10] P G Siddheshwar and S Pranesh, Effects of non-uniform temperature gradients and magnetic field on the onset of convection in fluids with suspended particles under microgravity conditions, Indian J. Engineering and Materials Sciences, vol. 8, pp. 7783, 2001.

[11] P G Siddheshwar and S Pranesh, Effects of a non-uniform basic temperature gradient on Rayleigh-Bénard convection in a micropolar fluid, International Journal of Engineering Science, vol. 36, pp. 1183-1196, 1998.

[12] P G Siddheshwar and S Pranesh, Effect of temperature / gravity modulation on the onset of magneto-convection in weak electrically conducting fluids with internal angular momentum, 212 
Journal of Magnetism and Magnetic Materials, vol. 192, pp. 159-176, 1999.

[13] P G Siddheshwar and S Pranesh, Magnetoconvection in fluids with suspended particles under $1 \mathrm{~g}$ and $\mu \mathrm{g}$, Int. J. Aerospace Science and Technology, vol. 6, pp. 105-114, 2001.

[14] P G Siddheshwar and S Pranesh, Linear and weakly nonLinear analyses of convection in a micropolar fluid, Hydrodynamics VI-Theory and Applications-Cheng and Yow (Eds.), pp. 487-493, 2005.

[15] S Pranesh and Riya Baby, Effect of non-uniform temperature gradient on the onset of Rayleigh-Bénard Electroconvection in a micropolar Fluid, Applied Mathematics, vol.3, pp.442-450, 2012.

[16] J C Maxwell, On the dynamical theory of gases, Phil. Trans. $R$. Soc. London, vol. 157, pp. 49-88, 1867.

[17] C Cattaneo, Sulla condizione del Calore, Atti del Semin.Matem.e Fis, Della Univ. Modena, vol. 3, pp. 83-101, 1948.

[18] Lindsay and B Stranghan, Penetrative convection instability of a micropolar fluid, Int. J. Engng. Sci., vol. 12, p. 1683, 1992.

[19] B Straughan and F Franchi, Bénard convection and the Cattaneo law of heat conduction, Proc. R. Soc. Edin., vol. 96A, pp. 175-178, 1984.

[20] S Pranesh and R V Kiran, Study of Rayleigh-Bénard magneto convection in a micropolar fluid with Maxwell-Cattaneo law, Applied Mathematics, vol. 1, pp. 470-480, 2010.

[21] S Pranesh and S N Smita, Rayleigh-Bénard convection in a second-order fluid with Maxwell-Cattaneo law, Bulletin of Society for mathematical services and standard, vol. 1, No. 2, pp. 33-48, 2012.

[22] P Puri and P M Jordan, Stokes's first problem for a dipolar fluid with nonclassical heat conduction, J. Engineering Mathematics, vol. 36, pp. 219-240, 1999.

[23] P Puri and P M Jordan, Wave structure in stokes second problem form dipolar fluid with nonclassical heat conduction, Acta Mech., vol. 133, pp. 145-160, 1999.

[24] P Puri and P K Kythe, Nonclassical thermal effects in stokes second problem, Acta Mech., vol. 112, pp. 1-9, 1995. 
[25] P Puri and P K Kyth, Discontinuities in velocity gradients and temperature in the Stokes first problem with nonclassical heat conduction, Quart. Appl. Math., vol. 55, pp. 167-176, 1997.

[26] B Straughan, Oscillatory convection and the Cattaneo law of heat conduction, Ricerche mat., vol. 58, pp. 157-162, 2009. 